\title{
Analysis of Sell-in-May-and-Go-Away Strategy on the Markets of 122 Equity Indices and 39 Commodities
}

\author{
Krzysztof Borowski ${ }^{1}$ \\ ${ }^{1}$ Warsaw School of Economics, Warsaw, Poland \\ Correspondence: Krzysztof Borowski, Warsaw School of Economics, Institute of Banking and Business \\ Insurance, Warsaw, 02-513, Poland. Tel: 48-510-275-217. E-mail: krzyztof.borowski@sgh.waw.pl
}

Received: August 27, 2015

Accepted: September 29, $2015 \quad$ Online Published: November 25, 2015

doi:10.5539/ijef.v7n12p119

URL: http://dx.doi.org/10.5539/ijef.v7n12p119

\begin{abstract}
The problem of efficiency of financial markets has always been one of the most important, including, among others, calendar effects. The sell-in-May-and-go-away (also called Halloween) effect is worth considering from the point of view of assessing the portfolio management effectiveness and behavioral finance. This paper tests the sell-in-May-and-go-away strategy and its modifications on the market of 122 equity indices and 39 commodities in the eight approaches, depending on the investment time horizon (October- $15^{\text {th }}$ May, November- $15^{\text {th }}$ May, October- $1^{\text {st }}$ May, November- $1^{\text {st }}$ May) and types of computed rates of return (accrued rates of return and average daily geometric rates of return). Calculations presented in this paper indicate the presence of the sell-in-May-and-go-away effect on the analyzed markets in the classic time frame, as well as in the different time frames.
\end{abstract}

Keywords: market efficiency, calendar anomalies, sell-in-May-and-go-away effect, Halloween effect

\section{Introduction}

Efficient market hypothesis (EMH), the center of the influential paper of Fama (1970), has been a cornerstone of financial economics for many decades. Although current definitions differ from that formulated by Fama, the efficiency of markets prevents regular market beating, usually in a form of above-average risk-adjusted returns. The problem of the financial markets efficiency, especially of equity markets, has been discussed in a number of academic works, which has led to a sizable set of publications examining this subject. In many empirical work dedicated to the time series analysis of rates of return and stock prices, there were found statistically significant effects of both types, i.e. calendar effects and effects associated with the size of companies. These effects are called "anomalies", because their existence testifies against market efficiency. Discussion of the most common anomalies in the capital markets can be found, among others, in Simson (1988) or Latif et al. (2011).

One of the calendar anomalies observed on the financial markets are:

a) Turn-of-the month effect-average rate of return calculated for the last day of the month and for three days of the next month, was higher than the average rate of return computed for the month, for which the rate of return of only one session, was taken (Cadsby \& Ratner, 1992). Lakonishok and Smidt (1988) found that the four days at the turn-of-the-month averaged a cumulative rate of increase of $0,473 \%$ versus $0,0612 \%$ for and average four days. The average monthly increase was $0,349 \%$, i.e., the DJIA went down during non-turn-of-the-month period.

b) Sell-in-May-and-go-away (also called Halloweeen) effect-the empirical evidence exhibited that during the period November-April rates of return are higher than the rates of return in the period May-October. The sell-in-May-and-go-away strategy was proposed by Hirsch in Stock Trader's Almanach, an annual publication since 1968. In the edition in 1997, Hirsch presented results of the sell-in-May-and-go-away strategy for DJIA for period of 1950-1996, proving that $\$ 10000$ investment grew to $\$ 206762$ and to $\$ 17272$ with the use of the November-April and May-October periods, respectively (Hirsch, 1997, p. 54). According to the assumption of the strategy, investors should avoid opening long position in equities in the period between May and November. In the financial literature, many variation of this strategy can be found. One of them concerning the futures contract on SP 500 and RUSELL indices, was proposed by Zacks (2011, p. 222): the long positions in equities should be closed on the first session in May and opened on the sixth trading day before the end of October. In 
case of SP 500 and RUSSELL 2000, the rate or return in the period 04.02.1993-31.12.2010 was equal to 96\% and $104 \%$, respectively, while the sell-in-May-and go-away strategy generated rate of return amounting to $273 \%$ and $394 \%$ respectively.

The aim of this paper is to examine the prevalence of sell-in-May-and-go-away strategy on the markets of 122 equity indices and 39 commodities. Analysis of the seasonality effects will apply to the returns calculated on the basis of the closing prices in eight approaches, depending on the investment horizon time span depending on the investment time horizon (October- $15^{\text {th }}$ May, November- $15^{\text {th }}$ May, October- $1^{\text {st }}$ May, November- $1^{\text {st }}$ May) and types of computed rates of return (accrued rates of return and average daily geometric rates of return).

In the scientific literature, the occurrence of Halloween effect was analyzed mainly in the stock market and not on the commodities market. This fact was a key reason for conducted statistical tests as well as an attempt to answer the question of whether this effect will occur for different maintenance asset periods.

\section{Literature Review}

Levis (1985) referred to the sell-in-May-and-go-away strategy but did not examine deeper this effect. O'Higgins and Downes (1990) provided result only for US market. Bouman and Jacobsen (2002) found the sell-in-May-and-go-away strategy in 36 out of 37 analyzed countries, including countries on the southern hemisphere, which, under their hypothesis, would be expected to have a different seasonal pattern. The authors found substantial difference between returns in the period May-October and the reminder of the year. The evidence proved that during the period November-April rates of return were significant in most analyzed countries but the average returns calculated for the period May-October were close to zero and often negative. Maberly and Pierce (2004) argued that the Bouman and Jacobsen's (2002) regression results might be caused by data outliers and comparing the Halloween strategy for SP 500 future contracts with the buy-and-hold strategy, rejected the first one as a profitable trading technique. The Maberly and Pierce's (2004) regression set up was impaired by Witte (2010), who proved that data outliers problem should be resolved, not by simply eliminating these data, but with the use of adequate regression methods. Lucey and Zhao (2008) analyzing the sell-in-May-and-go-away effect on the US market proved that this effect was weak. Jones and Lundstrum (2000) suggested that statistical test should focus rather on stock markets with liquid ETFs and future contracts. Jacobsen and Visaltanachoti (2006) proved the existence of the effect for two-third of the different analyzed US industries.

A link between seasonality and stock return was proposed by Kamstra et al. (2003) as well as by Garrett et al. (2004), who introduced Seasonal Affective Disorder (SAD), but Doeswijk (2005) argued that the historically high November returns cannot be explained by the SAD hypothesis because the SAD starts in September. According to Doeswijk (2005) the explanation of sell-in-May-and-go-away effect may be the overoptimism of investors in the last quarter of the year about the upcoming year. The excessive investors' optimism leads to higher rates of return followed by a readjusted expectations. In contrary to the SAD hypothesis, which suggest a varying risk premium, the Doeswijk (2005) explanation reflects a constant risk premium but a varying perception of the economic outlook (Zacks, 2011, p. 224). Data snooping, suggested by Sullivan et al. (2001) may be treated as an unlikely explanation for Halloween effect. The authors found that the discovery of commonly known calendar effects, e.g. January or Monday effect, might be spurious and a purely data-driven result.

The existence of Halloween effect was affirmed by several more recent studies (Jacobsen \& Zhang, 2012; Andrade et al., 2013; Swinkels \& van Vliet, 2012; Zhang \& Jacobsen, 2012; Dzhabarov \& Ziemba, 2010) but Dichtl and Drobetz (2014) could not confirm the fact, that the sell-in-May-and-go-away strategy generated higher rates of return compared to those of buy-and-hold. According to results of Zhang and Jacobsen (2012), the magnitude of the Halloween effect was fluctuating over time and varied depending on sample data. Swinkels and van Vliet (2012) proved the "turn of the month" and the Halloween effects to be the strongest calendar effects in the ample set of calendar anomalies. Furthermore the rates of return calculated for sell-in-May-and-go-away strategy, outperformed results for buy-and-hold strategy in the analyzed periods. The investment strategy analyzed by Andrade et al. (2013) based on SP 500 index, resulted in higher returns as well as in terms of Sharpe ratio for Halloween effect than in case of passive strategy. According to studies of Jacobsen and Zhang (2012), the risk-adjusted returns were higher in case of Halloween than buy-and-hold strategy on analyzed 108 equity markets. The Halloween strategy with the use of technical analysis was examined by Kaeppel (2009, pp. 220-246).

\section{Data and Methods}

The research is divided into eight parts. The calculation were proceeded regarding the following 122 world stock 
indices and 39 commodities (spot prices) availables in the Reuters service (see Appendix A).

For both stock indices and commodities last session taken into account in the process of calculating rates of return was 15.05.2015 (Friday) or in case of Arabic countries, the following session.

The adapted methodology in the paper can be divided into:

1) Testing the null hypothesis regarding equality of variances of rates of return in two populations;

2) Testing the null hypothesis regarding equality of averages rates of return in two populations.

\subsection{Testing the Null Hypothesis Regarding Equality of Variances of Rates of Return in Two Populations}

The null and alternative hypothesis can be formulated as follows:

$$
\begin{aligned}
& { }_{0}^{F} H: S_{1}^{2}=S_{2}^{2} \\
& { }_{1}^{F} H: S_{1}^{2} \neq S_{2}^{2}
\end{aligned}
$$

Where:

$S_{1}^{2}$ - variance of rates of return in the first population,

$S_{2}^{2}$ - variance of rates of return in the second population.

The first population is composed of the analyzed rates of return in the regime from 1 to 8 , and the second - of all the remaining rates of return-see 3.2.

As the last part of the calculation will be carried out using the F-statistics (so called Fisher-Snadecor statistics) for equality of variances of two population rates of return, where $F=\frac{S_{i}^{2}}{S_{j}^{2}}$, with the condition that: $S_{i}^{2}>S_{j}^{2}$ and the degrees of freedom are equal:

$n_{i}$ - for variance in the numerator of $F$,

$n_{j}$ - for variance in the denominator of $F$.

If F-test (computed for $\alpha=0,05$ ) is lower than F-statistics, e.g. the ratio F-test to F-statistics is lower than 1, there is no reason to reject the null hypothesis.

\subsection{Testing the Null Hypothesis Regarding Equality of Average Rates of Return in Two Populations}

According to the adopted methodology, the survey covers two populations of returns, characterized by normal distributions. On the basis of two independent populations of rate of returns, which sizes are equal $\mathrm{n}_{1}$ and $\mathrm{n}_{2}$, respectively, the hypotheses $H_{0}$ and $H_{l}$ should be tested with the use of statistics $z$ (Osinska, 2006, pp. 43-44):

$$
\mathrm{z}=\frac{\overline{\mathrm{r}_{1}}-\overline{\mathrm{r}_{2}}}{\sqrt{\left(\frac{\mathrm{s}_{1}^{2}}{\mathrm{n}_{1}}+\frac{s_{2}^{2}}{\mathrm{n}_{2}}\right)}}
$$

where:

$\overline{r_{1}}$-average rate of return in the first population,

$\overline{r_{2}}$-average rate of return in the second population,

The Formula 2 can be used in case of normally distributed populations, when the populations variances are unknown but assumed equal. The number of degrees of freedom is equal to: $d f(1)=n_{1}+n_{2}-2$.

When the populations variances are unequal, the number of degrees should be modified according to the following formula (Defusco et al., 2001, p. 335):

$$
d f(2)=\frac{\left(\frac{s_{1}^{2}}{n_{1}}+\frac{s_{2}^{2}}{n_{2}}\right)^{2}}{\frac{\left(S_{1}^{2} / n_{1}\right)^{2}}{n_{1}}+\frac{\left(S_{2}^{2} / n_{2}\right)^{2}}{n_{2}}}
$$

In case of two populations, both with equal or unequal variances, the null hypothesis $H_{0}$ and alternative hypothesis $H_{l}$ regarding equality of rates of return in two populations, can be formulated as follows:

$$
\begin{aligned}
H_{0}: E\left(r_{1}\right) & =E\left(r_{2}\right) \\
H_{1}: E\left(r_{1}\right) & \neq E\left(r_{2}\right)
\end{aligned}
$$


In all analyzed cases, the p-values will be calculated with the assumption that the populations variances are unknown, but:

a) population variances are assumed equal-p-value(1),

b) population variances are assumed unequal-p-value(2).

In case, when there is no reason to reject the null hypothesis about equality of variances of two observed returns, the $p$-value( 1 ) should be compared with the critical value 0,05 ; otherwise the $p$-value(2) will be used - that explains the reason of applying $p$-value in the following part of the paper. If the $p$-value ( $p$-value(1) or $p$-value(2)) is less than or equal to 0,05 ; then the hypothesis $H_{0}$ is rejected in favor of the hypothesis $H_{l}$. Otherwise, there is no reason to reject hypothesis $H_{0}$. In the part 3 of the paper, the $p$-value listed in the tables are equal to $p$-value(1) or $p$-value(2) depending on the result of testing the null hypothesis, concerning the equality of variance in the two populations of rates of returns.

The rates of return will be calculated in the following eight approaches:

1) Approach 1. The first population-accrued rate of return in the period: last session in October-the first session after $15^{\text {th }}$ May in the following year $\left(\overline{r_{1}}\right)$. The second population-accrued rate of return in the period: the first session after the $15^{\text {th }}$ May-the last session in November in the same year $\left(\overline{r_{2}}\right)$.

2) Approach 2. The first population-accrued rate of return in the period: last session in November-the first session after $15^{\text {th }}$ May in the following year $\left(\overline{r_{1}}\right)$. The second population-accrued rate of return in the period: the first session after the $15^{\text {th }}$ May-the last session in December in the same year $\left(\bar{r}_{2}\right)$.

3) Approach 3. The first population-accrued rate of return in the period: last session in October-the first session in May in the following year $\left(\bar{r}_{1}\right)$. The second population-accrued rate of return in the period: the first session in May-the last session in November in the same year $\left(\overline{r_{2}}\right)$.

4) Approach 4. The first population-accrued rate of return in the period: last session in November-the first session in May in the following year $\left(\bar{r}_{1}\right)$. The second population-accrued rate of return in the period: the first session on $15^{\text {th }}$ May-the last session in December in the same year $\left(\overline{r_{2}}\right)$.

5) Approach 5. The first population-average daily geometric rate of return in the period: last session in Octoberthe first session after $15^{\text {th }}$ May in the following year $\left(\overline{r_{1}}\right)$. The second population-average daily geometric rate of return in the period: the first session after the $15^{\text {th }}$ May-the last session in October in the same year $\left(\overline{r_{2}}\right)$.

6) Approach 6. The first population-average daily geometric rate of return in the period: last session in November-the first session after $15^{\text {th }}$ May in the following year $\left(\bar{r}_{1}\right)$. The second population-average daily geometric rate of return in the period: the first session after the $15^{\text {th }}$ May-the last session in November in the same year $\left(\overline{r_{2}}\right)$.

7) Approach 7. The first population-average daily geometric rate of return in the period: last session in Octoberthe first session in May in the following year $\left(\overline{r_{1}}\right)$. The second population-average daily geometric rate of return in the period: the first session in May-the last session in October in the same year $\left(\overline{r_{2}}\right)$.

8) Approach 8. The first population-average daily geometric rate of return in the period: last session in November-the first session in May in the following year $\left(\bar{r}_{1}\right)$. The second population-average daily geometric rate of return in the period: the first session in $15^{\text {th }}$ May-the last session in November in the same year $\left(\overline{r_{2}}\right)$.

The approach 3 may be considered as the classical sell-in-May-and-go-away effect and other approaches as its modifications. The purpose of using other approaches is to verify whether a similar effect occurs in other time frames, and for different prices (close / open).

\section{Results}

In the Results section, summarize the collected data and the analysis performed on those data relevant to the 
discourse that is to follow. Report the data in sufficient detail to justify your conclusions. Mention all relevant results, including those that run counter to expectation; be sure to include small effect sizes (or statistically nonsignificant findings) when theory predicts large (or statistically significant) ones. Do not hide uncomfortable results by omission. Do not include individual scores or raw data with the exception, for example, of single-case designs or illustrative examples. In the spirit of data sharing (encouraged by APA and other professional associations and sometimes required by funding agencies), raw data, including study characteristics and indivldual effect sizes used in a meta-analysis, can be made available on supplemental online archives.

\subsection{Approach 1}

The results of testing zero hypothesis with the use of average rates of returns for two different populations permit to draw the following conclusions:

1) The null hypothesis regarding equality of variances of accrued rates of return in two populations, was rejected (for $\alpha=5 \%$ ) in the following 61 cases: ADX Main, AEX, ATX, BEL 20, BET, BETI, CDAX, CNX NIFTY, CNX NIFTY TR, COLOMBIA SE, DAX, DJ Composite, DJIA, DJUA, EURONEX 100, FTSEMIB, FTSE 100, FTSE 250, FTSE Eurofirst, HANG SENG, HSCE, IBC, ISEQ, JKSE, MDAX, MERVAL, MSCI AC WORLD, MSCI WORLD, NEXT 150, NIKKEI, NZX 50, OBX, OMX Stockholm, OSE, PLE MAIN, PX, RUSSELL, SBITOP, SDAX, SET, SOFIX, SP ASX 200, SP 500, SSE B-shares, STXE 600 PR, TAIEX, TSE 300, VNI, WIG, canola, cocoa, corn, cotton, lead, palm oil, rapeseed, rubber, soybean, soybean oil, wheat, wheat KCBT.

2) The null hypothesis regarding equality of accrued rates of return in two populations was rejected for the following 26 indices and commodities ( $p$-value shown in parenthesis): ALL ORDINARIES $(0,0380)$, ATX $(0,0081)$, FTSE $250(0,0015)$, JCI $(0,0251)$, ISEQ $(0,0052)$, KARACHI $100(0,0491)$, KLCI $(0,0090)$, KLSE $(0,0287)$, NIKKEI $(0,0343)$, OMX Stockholm $(0,0346)$, OSE $(0,0033)$, PFTS $(0,0187)$, PSEI $(0,0116)$, SP TSX Composite $(0,0400)$, sWIG80 (0,0488), STXE 600 PR $(0,0320)$, TAIEX $(0,0202)$, TWII $(0,0018)$, UK $100(0,0043)$, UX $(0,0183)$, gasoline $(0,0001)$, heating oil $(0,0420)$, lean hogs $(0,0001)$, nickel $(0,0347)$, tin $(0,0347)$, wheat $(0,0001)$.

3) In all other cases, there was no reason to reject the null hypothesis in favor of the alternative hypothesis but the $p$-value higher than 0,05 and lower than 0,1 was registered in the following cases: AEX $(0,0665)$, ATHEX (0,0747), DJ Composite (0,0939), FTSE EUROTOP $100(0,0726)$, JKSE $(0,0915)$, MDAX $(0,0657)$, MICEX $(0,0600)$, PSI 20 (0,0664), PX (0,0728), RTS $(0,0996)$, SDAX (0,0594), Straits Times $(0,0764)$, VNI $(0,0949)$, palladium $(0,0565)$, rubber $(0,0856)$, soybean meal $(0,0798)$.

\subsection{Approach 2}

The results of testing zero hypothesis with the use of average rates of returns for two different populations permit to draw the following conclusions:

1) The null hypothesis regarding equality of variances of accrued rates of return in two populations, was rejected (for $\alpha=5 \%$ ) in the following 120 cases: AEX, ALL ORDINARIES, AMEX, AMM FT FLT, ATX, BB ALL Shares, BEL 20, BET, BETI, BOVESPA, BUMIX, CDAX, CNX NIFTY, CNX NIFTY TR, COLOMBIA SE, CRB, CSE ALL Shares, DAX, DJ Composite, DJIA, DJTA, DJUA, EOE, EURONEX 100, FTSEMIB, FTSE 100, FTSE 250, FTSE Eurofirst, FTSE EUROTOP 100, HEX, HANG SENG, HSCE, IBC, IBEX, ICEX, IPC, IPSA, JCI, ISEQ, JKSE, KARACHI 100, KLCI, KLSE, KOSPI, KW WEIGHTED IDW, MDAX, MERVAL, MSCI AC WORLD, MSCI WORLD, MSM MAIN 30, MSE, mWIG40, NASDAQ, NASDAQ 100, NEXT 150, NIKKEI, NZX 50, OBX, OMX Riga, OMX Stockholm, OMX Vilnius, OSE, PLE MAIN, PSEI, PX, RTS, RUSSELL, SAX, SDAX, SENSEX, SESESLTC, SET, SMI, SOFIX, SP 500, SP ASX 200, SP TSX Composite, SSE B-shares, SSE Composite, Straits Times, STXE 50 PR, STXE 600 PR, TAIEX, TDW MAIN, TECDAX, TOPIX, TSE 300, TUN MAIN, UK 100, VNI, WIG, XU 30, XU100, aluminum, aluminum ALLOY, Brent oil, canola, coal, copper, corn, cotton, crude oil, gas oil, gold, heating oil, lead, natural gas, nickel, palladium, palm oil, platinum, rapeseed, rubber, silver, soybean, soybean meal, soybean oil, tin, wheat, wheat KCBT.

2) The null hypothesis regarding equality of accrued rates of return in two populations was rejected for the following 5 indices and commodities (p-value shown in parenthesis): CNX NIFTY TR $(0,0499)$, gasoline $(0,0001)$, heating oil $(0,0442)$, lean hogs $(0,0001)$, wheat $(0,0004)$.

3) In all other cases, there was no reason to reject the null hypothesis in favor of the alternative hypothesis but the $p$-value higher than 0,05 and lower than 0,1 was registered in the following cases: OSE $(0,0701)$, TWII $(0,0524)$, VNI $(0,0580)$, palm oil $(0,0798)$, tin $(0,0951)$. 


\subsection{Approach 3}

The results of testing zero hypothesis with the use of average rates of returns for two different populations permit to draw the following conclusions:

1) The null hypothesis regarding equality of variances of accrued rates of return in two populations, was rejected (for $\alpha=5 \%$ ) in the following 76 cases: AEX, ALL ORDINARIES, AMEX, ATX, BEL 20, BET, BETI, CDAX, CNX NIFTY, CNX NIFTY TR, CRB, CSE ALL Shares, DAX, DJ Composite, DJIA, DJTA, DJUA, EURONEX 100, FTSEMIB, FTSE 100, FTSE 250, FTSE Eurofirst, HANG SENG, HSCE, IBC, IBEX, IPC, ISEQ, JKSE, MDAX, MERVAL, MSCI AC WORLD, MSCI WORLD, MSM MAIN 30, NASDAQ, NEXT 150, NIKKEI, NZX 50, OBX, OMX Stockholm, OMX Vilnius, OSE, PX, RUSSELL, SAX, SBITOP, SDAX, SESESLTC, SET, SOFIX, SP 500, SP ASX 200, STXE 600 PR, TA 100, TAIEX, TDW MAIN, TSE 300, UK 100, WIG, aluminum, aluminum ALLOY, canola, copper, corn, cotton, gas oil, lead, nickel, palm oil, platinum, rapeseed, rubber, soybean, soybean oil, wheat, wheat KCBT.

2) The null hypothesis regarding equality of accrued rates of return in two populations was rejected for the following 22 indices and commodities ( $p$-value shown in parenthesis): $\operatorname{AEX}(0,0353)$, ATX $(0,0081)$, FTSE 250 (0,0023), ISEQ $(0,0032)$, KLCI $(0,0313)$, KLSE $(0,0429)$, NIKKEI $(0,0408)$, OSE $(0,0158)$, PFTS $(0,0315)$, PSI $20(0,0388)$, PX $(0,0424)$, SP TSX Composite $(0,0480)$, STXE 600 PR $(0,0436)$, TAIEX $(0,0255)$, TWII $(0,0036)$, UK $100(0,0111)$, UX $(0,0337)$, gasoline $(0,0001)$, heating oil $(0,0340)$, lean hogs $(0,0001)$, tin $(0,0465)$, wheat $(0,0002)$.

3) In all other cases, there was no reason to reject the null hypothesis in favor of the alternative hypothesis but the $p$-value higher than 0,05 and lower than 0,1 was registered in the following cases: ALL ORDINARIES $(0,0528)$, ATHEX $(0,0681)$, DAX $(0,0709)$, FTSEMIB $(0,0879)$, FTSE EUROTOP $100(0,0732)$, KARACHI 100 (0,0594), MICEX (0,0520), OMX Stockholm $(0,0520)$, RTS $(0,0749)$, SDAX $(0,0775)$, sWIG80 $(0,0717)$, Straits Times $(0,0874)$, WIG20 $(0,0599)$, natural gas $(0,0671)$, nickel $(0,0575)$, palladium $(0,0955)$, soybean $(0,0665)$, soybean meal $(0,0907)$.

\subsection{Approach 4}

The results of testing zero hypothesis with the use of average rates of returns for two different populations permit to draw the following conclusions:

1) The null hypothesis regarding equality of variances of accrued rates of return in two populations, was rejected (for $\alpha=5 \%$ ) in the following 125 cases: AEX, ALL ORDINARIES, ALSIUG, AMEX, AMM FT FLT, ATX, BB ALL Shares, BEL 20, BET, BETI, BOVESPA, BUMIX, BUX, CDAX, CNX NIFTY, CNX NIFTY TR, COLOMBIA SE, CRB, CSE ALL Shares, CYMAIN, DAX, DJ Composite, DJIA, DJTA, DJUA, EGX 30, EGX 100, EOE, EURONEX 100, FTSEMIB, FTSE 100, FTSE 250, FTSE Eurofirst, FTSE EUROTOP 100, HANG SENG, HEX, HSCE, IBC, ICEX, IPC, IPSA, ISEQ, JCI, JKSE, KARACHI 100, KLCI, KLSE,KOSPI, KW WEIGHTED IDW, Lima General, MDAX, MERVAL, MSE, MSCI AC WORLD, MSCI WORLD, MSM MAIN 30, mWIG40, NASDAQ, NASDAQ 100, NEXT 150, NIKKEI, NZX 50, OBX, OMX Riga, OMX Stockholm, OMX Vilnius, OSE, PLE MAIN, PSEI, PX, RTS, RUSSELL, SAX, SDAX, SENSEX, SESESLTC, SET, SMI, SOFIX, SP ASX 200, SP 500, SP TSX Composite, SSE Composite, Straits Times, STXE 50 PR, STXE 600 PR, TA 100, TAIEX, TDW MAIN, TECDAX, TOPIX, TSE 300, UK 100, WIG, XU 30, XU 100, aluminum, aluminum ALLOY, Brent oil, canola, coal, coffee, copper, corn, cotton, crude oil, gas oil, gold, heating oil, lead, natural gas, nickel, palladium, palm oil, platinum, rapeseed, rubber, silver, soybean, soybean meal, soybean oil, tin, wheat, wheat KCBT, zinc.

2) The null hypothesis regarding equality of accrued rates of return in two populations was rejected for the following 4 indices and commodities ( $p$-value shown in parenthesis): gasoline $(0,0001)$, heating oil $(0,0354)$, lean hogs $(0,0001)$, wheat $(0,0007)$,

3) In all other cases, there was no reason to reject the null hypothesis in favor of the alternative hypothesis but the $p$-value higher than 0,05 and lower than 0,1 was registered in the following cases: CNX NIFTY TR $(0,0648)$, IPC $(0,0971)$, TWII $(0,0736)$, gold $(0,0966)$, palm oil $(0,0935)$.

\subsection{Approach 5}

The results of testing zero hypothesis with the use of average rates of returns for two different populations permit to draw the following conclusions:

1) The null hypothesis regarding equality of variances of average daily geometric rates of return in two populations, was rejected (for $\alpha=5 \%$ ) in the following 45 cases: AEX, ATX, BEL 20, BET, BETI, CDAX, DJ 
Composite, CROBEX, CNX NIFTY, CNX NIFTY TR, EURONEX 100, FTSE 100, FTSE 250, FTSE Eurofirst, HANG SENG, ISEQ, JKSE, MDAX, MSCI AC WORLD, MSCI WORLD, NEXT 150, OBX, OSE, PX, RTS, RUSSELL, SDAX, SOFIX, SP ASX 200, TAIEX, TSE 300, TUN MAIN, canola, cocoa, corn, gasoline, gold, lead, live cattle, orange juice, rubber, soybean oil, sugar, wheat, wheat KCBT,

2) The null hypothesis regarding equality of average daily geometric rates of return in two populations was rejected for the following 40 indices and commodities ( $p$-value shown in parenthesis): ALL ORDINARIES $(0,0136)$, AMEX $(0,0300)$, BET $(0,0449)$, BOVESPA $(0,0008)$, BUX $(0,0193)$, DAX $(0,0124)$, DJ Composite $(0,0006)$, DJIA $(0,0044)$, COLOMBIA SE $(0,0208)$, FTSE $250(0,0112)$, HANG SENG $(0,0078)$, IBC $(0,0003)$, IPC $(0,0041)$, IPSA $(0,0003)$, JCI $(0,0074)$, KARACHI $100(0,0038)$, Lima General $(0,0164)$, MDAX (0,0392), MICEX (0,0385), MERVAL $(0,0149)$, NASDAQ $(0,0001)$, NASDAQ $100(0,0076)$, NIKKEI $(0,0012)$, NZX $50(0,0255)$, OMX Stockholm $(0,0126)$, OSE $(0,0122)$, PSEI $(0,0455)$, QE Main $(0,0391)$, SENSEX (0,0015), SMI $(0,0316)$, SP $500(0,0020)$, SP ASX $200(0,0445)$, STXE 600 PR $(0,0419)$, UK $100(0,0073)$, TA 100 (0,0366), TSE $300(0,0340)$, TUN MAIN $(0,0088)$, WIG $(0,0269)$, XU 100 $(0,0009)$, gold $(0,0179)$.

3) In all other cases, there was no reason to reject the null hypothesis in favor of the alternative hypothesis but the $p$-value higher than 0,05 and lower than 0,1 was registered in the following cases: AEX $(0,0695)$, ALSIUG $(0,0680)$, CASA ALL Shares $(0,0809)$, CNX NIFTY TR $(0,0760)$, DJTA $(0,0522)$, FTSE EUROTOP $100(0,0915), \operatorname{JKSE}(0,0510), \operatorname{KLCI}(0,0744)$, KOSPI $(0,0706)$, OMX Talin $(0,0836)$, SESESLTC $(0,0534)$, SSE Composite $(0,0669)$, STXE 50 PR $(0,0504)$, TWII $(0,0503)$, XU $30(0,0637)$.

\subsection{Approach 6}

The results of testing zero hypothesis with the use of average rates of returns for two different populations permit to draw the following conclusions:

1) The null hypothesis regarding equality of variances of average daily geometric rates of return in two populations, was rejected (for $\alpha=5 \%$ ) in the following 35 cases: AEX, BETI, CRB, EURONEX 100, FTSE Eurofirst, ICEX, ISEQ, MDAX, MSCI AC WORLD, MSCI WORLD, NEXT 150, OBX, OSE, PLE MAIN, SDAX, SAX, SP ASX 200, SP TSX Composite SSE B-shares, STXE 600 PR, TAIEX, TSE 300, TUN MAIN, TWII, VNI, cocoa, gas oil, gold, lead, lean hogs, live cattle, lumber, orange juice, rubber, silver, sugar.

2) The null hypothesis regarding equality of average daily geometric rates of return in two populations was rejected for the following 44 indices and commodities ( $p$-value shown in parenthesis): ALL ORDINARIES $(0,0161)$, ALSIUG $(0,00183)$, AMEX $(0,0214)$, BET $(0,0385)$, BOVESPA $(0,0004)$, BUX $(0,0176)$, COLOMBIA SE $(0,0237)$, DAX $(0,0090)$, DJ Composite $(0,0004)$, DJIA $(0,0081)$, DJTA $(0,0399)$, FTSE 250 $(0,0028)$, HANG SENG $(0,0081)$, IBC $(0,0005)$, IPC $(0,0062)$, IPSA (0,0002), JCI $(0,0157)$, KARACHI 100 $(0,0408)$, KLCI $(0,0408)$, Lima General $(0,0083)$, MDAX $(0,0102)$, MERVAL $(0,0100)$, NASDAQ $(0,0001)$, NASDAQ $100(0,0073)$, NIKKEI $(0,0012)$, NZX 50 (0,0259), OMX Stockholm $(0,0060)$, OSE $(0,0017)$, PSEI (0,0300), QE Main $(0,0345)$, SENSEX (0,0018), SESESLTC $(0,0498)$, SMI $(0,0267)$, SP $500(0,0019)$, SP ASX 200 (0,0361), STXE 600 PR (0,0352), TA 100 (0,0415), TUN MAIN $(0,0051)$, TWII $(0,0096)$, UK $100(0,0014)$, XU $100(0,0020)$, gasoline $(0,0210)$, gold $(0,0237)$, lean hogs $(0,0332)$.

3) In all other cases, there was no reason to reject the null hypothesis in favor of the alternative hypothesis but the $p$-value higher than 0,05 and lower than 0,1 was registered in the following cases: AEX $(0,0610)$, BETI $(0,0978)$, CASA ALL Shares (0,0553), CDAX (0,0906), FTSE EUROTOP $100(0,0595)$, JKSE $(0,0590)$, KOSPI (0,0660), MICEX $(0,0570)$, NSE ALL Shares $(0,0992)$, OBX $(0,0994)$, OMX Talin $(0,0640)$, SDAX $(0,0730)$, SSE Composite $(0,0573)$, STXE 50 PR $(0,0620)$, sWIG80 $(0,0574)$, TSE $300(0,0579)$, WIG $(0,0679), \mathrm{XU} 30(0,0813)$.

\subsection{Approach 7}

The results of testing zero hypothesis with the use of average rates of returns for two different populations permit to draw the following conclusions:

1) The null hypothesis regarding equality of variances of average daily geometric rates of return in two populations, was rejected (for $\alpha=5 \%$ ) in the following 80 cases: ADX Main, AMM FT FLT, AT COMPOSITE SHR PR, AT FTSE ASE 20, ATX, BEL 20, BB ALL Shares, BETI, CAS A ALL Shares, CNX NIFTY, COLOMBIA SE, CROBEX, CSE ALL Shares, DJTA, EURONEX 100, FTSE EUROTOP 100, FTSE Eurofirst, HSCE, ISEQ, JKSE, KARACHI 100, KLSE, KW MAIN, KW WEIGHTED IDW, Lima General, MDAX, MSCI AC WORLD, MSCI WORLD, MSE, MSM MAIN 30, NEXT 150, NSE ALL Shares, OBX, OSE, PFTS, PLE MAIN, QE Main, RTS, SAX, SDAX, SP ASX 200, STXE 50 PR, STXE 600 PR, TA 
100, TAIEX, TUN MAIN, TWII, UK 100, VNI, WIG, XU 30, barley, Brent oil, canola, coal, cocoa, corn, cotton, crude oil, gas oil, gasoline, gold, heating oil, lead, lead, lean hogs, live cattle, lumber, natural gas, orange juice, palm oil, rapeseed, rubber, rough rice, soybean, soybean meal, soybean oil, sugar, wheat, wheat KCBT.

2) The null hypothesis regarding equality of average daily geometric rates of return in two populations was rejected for the following 52 indices and commodities ( $p$-value shown in parenthesis): AEX $(0,0391)$, ALL ORDINARIES $(0,0071)$, ALSIUG $(0,0281)$, AMEX $(0,0253)$, AMM FT FLT $(0,0060)$, BET $(0,0262)$, BUX $(0,0158)$, CNX NIFTY $(0,0051)$, CNX NIFTY TR $(0,0173)$, CROBEX $(0,0174)$, DAX $(0,0051)$, DJ Composite $(0,0002)$, DJIA $(0,0019)$, DJTA $(0,0004)$, EGX $30(0,0010)$, FTSE $250(0,0039)$, FTSE EUROTOP $100(0,0168)$, HANG SENG $(0,0060)$, IBC $(0,0001)$, IPC $(0,0034)$, IPSA $(0,0002)$, ISEQ $(0,0040)$, JCI $(0,0056)$, JKSE $(0,0011), \operatorname{KLCI}(0,0433), \operatorname{KLSE}(0,0103), \operatorname{KOSPI}(0,0471), \operatorname{MDAX}(0,0211)$, MICEX $(0,0104)$, NASDAQ $(0,0001)$, NASDAQ 100 (0,0076), NIKKEI $(0,0007)$, NZX $50(0,0153)$, OMX Stockholm $(0,0084)$, OSE $(0,0050)$, PFTS $(0,0327)$, PSEI $(0,0388)$, QE Main $(0,0240)$, SENSEX $(0,0035)$, SESESLTC $(0,0465)$, SMI $(0,0341)$, SP $500(0,0012)$, SP ASX $200(0,0197)$, STXE 600 PR $(0,0159)$, TA 100 $(0,0177)$, TSE $300(0,0127)$, TWII $(0,0209)$, UK $100(0,0045)$, WIG $(0,0247)$, XU $100(0,0008)$, gold $(0,0166)$, rubber $(0,0177)$.

3) In all other cases, there was no reason to reject the null hypothesis in favor of the alternative hypothesis but the $p$-value higher than 0,05 and lower than 0,1 was registered in the following cases: ATX $(0,0757)$, BETI $(0,0811)$, CASA ALL Shares $(0,0884)$, CDAX (0,0693), FTSE 100 (0,0790), Lima General $(0,0955)$, MSE $(0,0501)$, MSM MAIN $30(0,0642)$, NEXT $150(0,0956)$, OBX $(0,0762)$, OMX Talin $(0,0586)$, SSE Composite $(0,0583)$, sWIG80 $(0,0928)$, TDW MAIN $(0,0534)$, TUN MAIN $(0,0719)$, XU $30(0,0887)$, palm oil $(0,0557)$, soybean $(0,0984)$.

\subsection{Approach 8}

The results of testing zero hypothesis with the use of average rates of returns for two different populations permit to draw the following conclusions:

1) The null hypothesis regarding equality of variances of average daily geometric rates of return in two populations, was rejected (for $\alpha=5 \%$ ) in the following 90 cases: ADX Main, AMM FT FLT, ALSIUG, AT COMPOSITE SHR PR, AT FTSE ASE 20, ATHEX, ATX, BELEX 15, BB ALL Shares, BETI, CASA ALL Shares, CNX NIFTY, CNX NIFTY TR, COLOMBIA SE, CRB, CROBEX, CSE ALL Shares, CYMAIN, DFM MAIN, DJTA, EGX 30, EURONEX 100, FTSE EUROTOP 100, HSCE, IBC, ICEX, ISEQ, JKSE, KARACHI 100, KLSE, KW MAIN, KW WEIGHTED IDW, Lima General, MBI 10, MSE, MSCI AC WORLD, MSCI WORLD, MSM MAIN 30, NASDAQ, NEXT 150, NIKKEI, NSE ALL Shares, PFTS, PSEI, QE Main, SAX, SBITOP, SENSEX, SP ASX 200, STXE 50 PR, SP TSX Composite, SSE B-shares, STXE 600 PR, TA 100, TAIEX, TDW MAIN, TUN MAIN, TWII, UK 100, VNI, XU 30, barley, Brent oil, canola, coal, cocoa, coffee, corn, cotton, crude oil, gas oil, gasoline, gold, heating oil, lumber, lead, lean hogs, live cattle, natural gas, orange juice, palm oil, rapeseed, rubber, rough rice, silver, soybean, soybean meal, sugar, wheat, wheat KCBT,

2) The null hypothesis regarding equality of average daily geometric rates of return in two populations was rejected for the following 48 indices and commodities ( $p$-value shown in parenthesis): ADX Main $(0,0389)$, AEX $(0,0366)$, ALL ORDINARIES $(0,0110)$, ALSIUG $(0,0445)$, AMEX $(0,0170)$, AMM FT FLT $(0,0010)$, BET $(0,0309)$, BUX $(0,0147)$, CROBEX $(0,0178)$, CSE ALL Shares $(0,0491)$, DAX $(0,0027)$, DJ Composite (0,0002), DJIA (0,0037), DJTA (0,0151), EGX $30(0,0008)$, EGX $100(0,0001)$, FTSE 250 $(0,0016)$, HANG SENG $(0,0086)$, IPC $(0,0055)$, IPSA $(0,0001)$, ISEQ $(0,0056)$, JCI $(0,0177)$, KLCI $(0,0335)$, KOSPI (0,0342), MDAX (0,0059), MICEX (0,0311), MERVAL (0,0067), MSM MAIN $30(0,0051)$, NASDAQ (0,0002), NASDAQ $100(0,0068)$, NIKKEI (0,0007), NZX 50 (0,0171), OMX Stockholm $(0,0033)$, OSE $(0,0008)$, PSEI $(0,0429)$, SDAX $(0,0460)$, SSE Composite $(0,0426)$, SENSEX $(0,006)$, SESESLTC $(0,0364)$, SMI $(0,0332)$, SP $500(0,0011)$, sWIG80 $(0,0492)$, TA $100(0,0966)$, TSE $300(0,0454)$, UK 100 $(0,0013)$, XU 100 (0,0014), gold $(0,0277)$, lean hogs $(0,0167)$,

3) In all other cases, there was no reason to reject the null hypothesis in favor of the alternative hypothesis but the $p$-value higher than 0,05 and lower than 0,1 was registered in the following cases: CDAX $(0,0816)$, IBEX $(0,0755)$, KARACHI $100(0,0863)$, OMX Talin $(0,0532)$, RTS $(0,0811)$, Straits Times $(0,0994)$, TDW MAIN $(0,0581)$, WIG $(0,0650)$, live cattle $(0,0922)$. 


\section{Discussion}

The aim of this study was to determine the prevalence of the sell-in-May-and-go-away effect on the markets of 122 equity indices and 39 commodities. Analysis of the effects of seasonality included an examination of the rates of return calculated for eight approaches, depending on the investment horizon time span and on the type of calculated rate or return.

Calculations presented in this paper indicate the presence of the Halloween effect and its modifications in the following cases (in descending order):

a) average daily geometric rates of return:

- $7^{\text {th }}$ approach -52 (50 stock indices and 2 commodities),

- $8^{\text {th }}$ approach -48 (46 stock indices and 2 commodities),

- $6^{\text {th }}$ approach -44 (41 stock indices and 3 commodities),

- $5^{\text {th }}$ approach -40 (39 stock indices and 1 commodity).

b) accrued rates of return:

- $1^{\text {st }}$ approach - 26 (20 stock indices and 6 commodities),

- $\quad 3_{\text {rd }}$ approach - 22 (17 stock indices and 5 commodities),

- $\quad 2^{\text {nd }}$ approach -5 (1 stock indices and 4 commodities),

- $4^{\text {th }}$ approach -4 ( 0 stock indices and 4 commodities).

The existence of seasonality effects occurred in both developed and emerging stock markets as well as on the commodity markets. The Halloween effect was observed in its basic version (approach 3) and also in its modifications (approaches: 1-2 and 4-8). In case of the approach 4, the sell-in-May-and-go-away effect was registered only on the commodity market.

Results obtained in the research regarding the sell-in-May-and-go-away effect on the equity market are consistent with those of Bouman and Jacobsen (2002), Jacobsen and Zhang (2012), Andrade et al. (2013), Swinkels and van Vliet (2012), Zhang and Jacobsen (2012), Dzhabarov and Ziemba (2010) and Kaeppel (2009, pp. 220-246).

The main limitation of this research is the assumption of normal distribution of return rates of analyzed indices and commodities along with the use of price data gained from Reuters data source as well as the unequal intervals of observations for different equity indices and commodities.

Further research on the occurrence of Halloween effect and its modifications in the financial markets should cover the currency market.

The outcome may be regarded as a part of the ongoing discussions on the hypothesis of financial markets efficiency, which was introduced by Fama (1970).

\section{References}

Andrade, S., Chhaochharia, V., \& Fuerst, M. (2013). Sell in May and go away, just won’t go away. Financial Analyst Journal, 69(4), 94-105. http://dx.doi.org/10.2469/faj.v69.n4.4

Bouman, B., \& Jacobsen, B. (2002). The Halloween indicator, sell in May and go away: Another puzzle. American Economic Review, 92(5), 1618-1635. http://dx.doi.org/10.1257/000282802762024683

Cadsby, C., \& Ratner, M. (1992). Turn-of-month and pre-holiday effects on stock returns: Some international $\begin{array}{lllll}\text { evidence. Journal of Banking and } & \text { Finance, 16(3), }\end{array}$ http://dx.doi.org/10.1016/0378-4266(92)90041-W

Defusco, R., McLeavey D., Pinto J., \& Runkle, D. (2001). Quantitative methods for investment analysis. Baltimore: United Book Press.

Dichtl, H., \& Drobetz, W. (2014). Are stock markets really so inefficient? The case of the "Halloween indicator". Finance Research Letters, 11(2), 112-121. http://dx.doi.org/10.1016/j.frl.2013.10.001

Doeswijk, R. (2005). The optimism cycle: Sell in May. De Economist, 156(2), 175-200. http://dx.doi.org/10.1007/s10645-008-9088-z

Dzhabarov, C., \& Ziemba, W. (2010). Do seasonal anomalies still work? Journal of Portfolio Management, 36(3), 93-104. http://dx.doi.org/10.3905/jpm.2010.36.3.093

Fama, E. (1970). Efficient capital markets; A review of theory and empirical work. Journal of Finance, 25(2), 
383-417. http://dx.doi.org/10.2307/2325486

Garrett, I., Kamstra, M., \& Kramer, A. (2004). Winter blues and time variation in the price of risk. Journal of Empirical Finance, 12(2), 291-316. http://dx.doi.org/10.1016/j.jempfin.2004.01.002

Hirsch, Y. (1997). Stock Traders Almanac. Old Tappen, NJ: The Hirsch Organization.

Jacobsen, B., \& Zahng, C. (2012). The Halloween indicator: Everywhere and all the time. Working paper, Massey University.

Jacobsen, B., \& Visaltanachoti, N. (2006). The Halloween effect in US sectors. Financial Review, 44, 437-459.

Jones, C., \& Lundstrum, L. (2009). Is "Sell in May and go away" a valid strategy for US equity allocation?. Journal of Wealth Management, 12, 104-112.

Kaeppel, J. (2009). Seasonal stock market trends. Hoboken: Wiley and Sons.

Kamsta, M., Kramer, L., \& Levi, M. (2003). Winter blues: A SAD stock market cycle. Federal Reserve Bank of Atlanta Working Paper, No. 2002-13a.

Lakonishok, J., \& Shmidt, S. (1988). Are seasonal anomalies real. A ninety-year perspective. Review of Financial Studies, 1(4), 403-425. http://dx.doi.org/10.1093/rfs/1.4.403

Latif, M., Arshad, S., Fatima, M., \& Rarooq, S. (2011). Market efficiency, market anomalies, causes, Evidences and some behavioral aspects of market anomalies. Research Journal of Finance and Accounting, 2, 1-14.

Levis, M. (1985). Are small firms big performers?. Investment Analysis, 76, 21-27.

Lucey, B., \& Zhao, S. (2008). Halloween or January? Yet another puzzle. International Review of Financial Analysis, 17(5), 1055-1069. http://dx.doi.org/10.1016/j.irfa.2006.03.003

Maberly, E., \& Pierce, R. (2004), Stock market efficiency withstands another challenge: Solving the "Sell in May/buy after Halloween" puzzle. Economic Journal Watch, 1, 29-46.

O'Higgins, M., \& Downes, J. (1990). Beating the Dow, a high-return-low-risk method for investing in industrial stocka with as little as \$5000. New York: Harper Collins.

Osińska, M. (2006). Ekonometria finansowa. Warszawa: PWE.

Simson, E. (1988). Stock market anomalies. Cambridge: Cambridge University Press.

Sullivan, R., Timmermann, A., \& White, R. (2001). Dangers of Data Mining. The case of calendar effects in stock returns. Journal of Conometrics, 105(1), 249-286. ttp://dx.doi.org/10.1016/S0304-4076(01)00077-X

Swinkels, L., \& Van Vliet, P. (2012), An anatomy of calendar effects. Journal of Asset Management, 13(4), 271-286. http://dx.doi.org/10.1057/jam.2012.9

Witte, H. (2010). Outliers and the Halloween effect: comment on Maberly and Pierce. Economic Journal Watch, 7, 91-98.

Zacks, L. (2011). The Handbook of equity market and anomalies. Hoboken: Wiley \& Sons.

Zhang, C., \& Jacobsen, B. (2012). Are monthly seasonal real? A three century perspective. Review of Finance, 17(5), 1743-1785. http://dx.doi.org/10.1093/rof/rfs035

\section{Appendix A}

\section{The List of analyzed equity indices and commodities}

World stock indices (in brackets the date of the first session included in the analysis):

ADX Main (01.07.2001), AEX (03.01.1983), ALL ORDINARIES (01.01.1980), ALSIUG (03.08.2004), AMEX (03.01.1995), AMM FR FLT (29.12.1999), AT COMPOSITE SHR PR (02.01.1991), AT FTSE ASE 20 (17.11.1997), ATHEX (02.01.1987), ATX (08.01.1986), BB ALL Shares (02.01.2003), BEL 20 (01.01.1991), BELEX 15 (04.10.2005), BET (31.10.2000), BETI (22.09.1997), BOVESPA (12.07.1989), BUMIX (01.06.2004), BUX (02.01.1991), CASA ALL Shares (02.01.2002), CDAX (15.03.2004), CNX NIFTY (03.11.1995), CNX NIFTY TR (30.06.1999), COLOMBIA SE (03.07.2001), CRB (03.01.1994), CROBEX (15.01.1998), CSE ALL Shares (14.06.1993), CYMAIN (06.09.2004), DAX (28.09.1959), DFM Main (31.12.2003), DJ Composite (23.12.1980), DJIA (02.01.1900), DJTA (02.01.1990), DJUA (02.01.1929), EGX 30 (01.01.1998), EGX 70 (02.01.2006), EOE (02.01.1995), EURONEX 100 (31.12.1999), FTSE 100 (22.10.1992), FTSE 250 (31.12.1985), FTSE Eurofirst (28.07.1997), FTSE EUROTOP 100 (01.07.1997), FTSEMIB 
(02.01.1998), HANG SENG (21.11.1969), HEX (02.01.1995), HSCE (17.07.1993), IBC (31.12.1993), IBEX (05.01.1987), ICEX (31.12.1992), IPC (08.11.1991), IPSA (02.01.1987), ISEQ (01.03.1989), JCI (04.04.1983), JKSE (06.04.1994), KARACHI 100 (25.05.1994), KLCI (03.01.1977), KLSE (04.01.1982), KOSPI (14.01.1980), Lima General (02.01.1992), KW MAIN (05.03.1997), KW WEIGHTED IDW (16.12.2000), MBI 10 (31.12.2004), MDAX (29.02.1996), MICEX (22.09.1997), MERVAL (04.04.1988), MSE (27.12.1995), MSCI WORLD (14.07.2003), MSCI AC WORLD (14.07.2003), MSM MAIN 30 (01.01.1992), mWIG40 (31.12.1997), NASDAQ (03.01.1938), NASDAQ 100 (01.10.1985), NEXT 150 (31.12.1999), NIKKEI (01.05.1949), NSE ALL Shares (14.01.2000), NZX 50 (03.01.2003), OBX (07.09.1999), OMX Riga (03.01.2000), OMX Stockholm (30.09.1986), OMX Talin (03.01.2000), OMX Vilnius (01.01.2000), OSE (03.01.1983), SAX (03.07.1995), sWIG80 (29.12.1994), PFTS (03.10.1997), PLE MAIN (11.02.1997), PSEI (02.01.1986), PSI 20 (31.12.1992), PX (07.09.1993), QE Main (10.08.1998), RTS (01.09.1995), RUSSELL (22.10.2001), SAX (21.09.1993), SBITOP (04.04.2006), SDAX (15.03.1999), SENSEX (03.04.1979), SESESLTC (02.01.2003), SET (02.07.1987), SMI (01.07.1988), SOFIX (26.11.2001), SP 500 (02.01.1900), SP ASX 200 (29.05.1992), SP TSX Composite (03.01.1961), SSE B-shares (04.01.2000), SSE Composite (19.12.1990), Straits Times (28.12.1987), STXE 50 PR (31.12.1986), STXE 600 PR (31.12.1986), TA 100 (08.10.1992), TAIEX (05.01.1995), TDW MAIN (19.10.1998), TECDAX (16.09.1999), TOPIX (22.10.2001), TSE 300 (15.08.1989), TUN MAIN (31.12.1997), TWII (05.01.1970), UK 100 (13.11.1935), UX (03.11.1997), VNI (28.07.2000), WIG (16.04.1991), WIG20 (14.04.1994), XU 30 (01.01.1997), XU 100 (02.01.1990).

The CRB index is a commodity index but as an index was classified to the group of the equity indices.

Commodities (in brackets the date of the first quotation included in the analysis)-spot prices:

Aluminum ALLOY (04.01.1993), aluminum (03.01.1989), barley (11.12.2006), Brent oil (30.03.1983), canola (01.09.1998), coal (23.08.2001), cocoa (01.07.1959), coffee (17.08.1973), copper (01.01.1950), corn (01.03.1968), cotton (01.07.1959), crude oil (04.04.1983), feeder cattle (06.09.1973), gas oil (01.09.1998), gasoline (01.09.1998), gold (02.06.1969), heating oil (06.03.1979), nickel (03.01.1989), lead (03.01.1989), lean hogs (25.06.1969), live cattle (05.01.1970), lumber (01.09.1998), natural gas (31.01.1997), orange juice (01.02.1967), palladium (05.01.1977), palm oil (23.10.1980), platinum (01.03.1968), rapeseed (22.11.1994), rubber (23.01.1990), rough rice (01.09.1987), silver (13.06.1963), soybean (01.07.1959), soybean meal (01.09.1998), soybean oil (01.09.1998), sugar (01.04.1969), tin (03.07.1989), wheat (01.07.1959), wheat KCBT (01.09.1998), zinc (03.01.1989).

\section{Copyrights}

Copyright for this article is retained by the author(s), with first publication rights granted to the journal.

This is an open-access article distributed under the terms and conditions of the Creative Commons Attribution license (http://creativecommons.org/licenses/by/3.0/). 